\title{
Study of teenage students' musculoskeletal health, teenage students training program: the application of intervention mapping approach to Develop Implementation Strategies
}

Nazila NeJhaddadgar

Ardabil University of Medical Sciences: Ardebil University of Medical Sciences

Sedigheh Sadat Tavafian ( $\sim$ tavafian@modares.ac.ir)

Tarbiat Modares University Faculty of Medical Sciences

arash ziapour ( $\sim$ arashziapoor@gmail.com )

Kermanshah University of Medical Sciences https://orcid.org/0000-0001-8687-7484

Jaffar Abbas

Shanghai Jiao Tong University Medical Library: Shanghai Jiao Tong University School of Medicine Ahmad Rreza Jamshidi

Tehran University: University of Tehran

\section{Research}

Keywords: Health education, Adolescent, Musculoskeletal health, Intervention mapping

Posted Date: May 12th, 2021

DOI: https://doi.org/10.21203/rs.3.rs-485969/v1

License: (c) (1) This work is licensed under a Creative Commons Attribution 4.0 International License.

Read Full License 


\section{Abstract}

Background: According to the studies conducted, teenage and its related health issues are of the most significant issues. The purpose of the study was to develop a Musculoskeletal Health interventiontraining program using intervention mapping approach (IMA)for teenagers 12 to 14 years old.

Methods: The present study is a study protocol where IMA has been used as a planning framework for developing musculoskeletal Health intervention-training program. Six intervention mapping steps have been completed in the study. As the first step, needs assessment has been performed by systematic review and qualitative evaluation . In the second step, matrix of change objectives was designed. Later on, after designing the program and planning the program implementation, the program evaluation plan was developed.

Results: IMA guided us in designing and implementing a control-oriented training program with the participation of the participants along with the definition of outcomes, performance goals and determinants, theoretical methods and practical applications, intervention program, implementation and step by step assessment.

Conclusion: Intervention mapping is a participation-based approach to design and implement promotion programs.

\section{Background}

According to the statute of the World Health Organization (WHO), health is considered as one of the most obvious human rights and needs [1]. Teenage is one of the most significant periods in every person's life [2]. According to a report by WHO, one out of every five people is adolescent [3]. Today, the backpack is one of the most popular kinds of bags among teenage students which has been noticed by many researchers from different aspects since backpack is one of the most important factors which creates musculoskeletal injuries in teenage students [4, 5]. A heavy backpack makes a person arche his/her back more than usual or bend his/her head and pull forward his body to tolerate the weight of the backpack. And the pressure on the muscles of the neck and back can cause fatigue, injury, and finally anomalies of the spine [6]. American Academy of Orthopedic Surgeons stated that the properties of a good backpack are having two shoulder straps, back pads, waistband, low weight, and wheels [7]. In different ages, the effect of cargo transportation varies. During 12-14 years old, the spine is growing rapidly and any kind of stress on the spine manifests itself as pain and discomfort [8]. These studies showed that when the weight of backpacks is more than the specified standard it leads to pain in the back and the upper parts of the body. Also, carrying these bags, in the long run, leads to drooping shoulders and kyphosis [9].

In recent years, carrying and using tools and backpacks has been considered as risk factors for musculoskeletal disorders [10-13]. The findings of some studies show that between 40 and 88 percent of students complain about the pain on their shoulders, neck, and back when they carry their backpacks. 
Moreover, between 30 to 80 percent of them believe that their musculoskeletal problems are related to carrying backpacks [10].

Training is a process that bridges the gap between health information and behavior, and given the relationship between knowledge, attitude and performance improvement in an intervention-training process, the significance of proper information provision and the provision of learning opportunities for Teenage students become evident [11]. Designing a targeted intervention program needs using an evidence-based planning framework, the theory and curriculum for adolescent special education programs. Different models have been developed for designing, implementing, and evaluation of training programs by experts, one of which is IMA[9]. This approach is a planning approach based on the significance of developing evidence-based programs that assess and intervene in health-related issues [10].

IMA aims to provide guidelines for effective decision-making during the development and adaptation of an intervention, integrating theory, empirical findings, and information from the target population also has a problem solving-based approach and enables the implementation of the program through six steps: need assessment, objectives matrix design, selection of theory and practical application-based intervention methods, production of components and materials of the intervention program, adoption planning, implementation and sustainability and evaluation [11]. This approach focuses on behavioral change and the individuals who are influential on the behavior of those at risk known as environmental agents and individuals' health issues at different ecological levels to make changes [12]. The aim of the current study is to prepare an intervention plan to reduce musculoskeletal damage due to the use of a backpack in adolescents 12 to 14 years.

\section{Methods}

The present study is the description of a study conducted to develop a training-intervention program using IMA in adolescents 12 to 14 years in the year 2020. Intervention mapping has six steps and some tasks at each step, where the basic processes are used in completing each step to benefit from theories and models.

\section{Step 1: Needs assessment}

we conducted a needs assessment based on the PRECEDE/PROCEED model to identify the factors the program should address. As the first part of intervention mapping, needs assessment is defined as a systematic study to identify the difference between what the status is and what should be in a given group and the intended state $[13,14]$. In the current study, the planning group was established to identify the health issue, and examine the life quality of teenage students with the presence of stakeholders in health education, Orthopedic specialist, school principals, health educators, mothers, and student, was examined using health needs assessment group, life quality, and behavioral and environmental determinants using PRECEDE model [15]. This assessment was done using systematic review and a 
qualitative study was. Finally, the results of the needs assessment were determined by identifying the health and life quality outcomes of the evaluation program.

In the systematic review over the studies conducted to select the papers, Pubmed, scoups, Embase, and Google Scholar databases were searched for English papers and Iranmedex, SID, and Google Scholar databases for Persian ones. Given the differences in searching Iranian and foreign scientific databases, various Persian and English keywords were selected. The search was performed based on keywords among the papers of the past 5 years and focused on the keywords of "Backpack," "Musculoskeletal Injuries," and "Adolescent "from MESH and selected 14 out of 210 articles based on the research objective. According to the Crombie Checklist, inclusion and exclusion criteria, and investigating the quality of the report, this

review focused on systematic evidence to the field under investigation. Based on the chosen 14 articles.

Since the research method in this study is qualitative, the data was obtained through interview and the process of interview continued until data saturation. In this step after coordination, an invitation letter was sent to all health educators and mothers of teenage students (12-14 years) in Ardabil to participation. The samples were selected using purposive and voluntary sampling methods, and the main criterion for the inclusion was the individuals' willingness to participate in interviews and their interest in working with project executives. After obtaining informed consent, the data were collected through 15 school health educators, 23 mothers, and 20 teenage students (12-14 years) was interviewed also the length of interview was varied between 30 to 40 minutes. The sessions were conducted by the researcher using semi-structured and the questions were open- ended. In addition, the questions during interview were simple, understandable and clear, and academic language and professional accent were not used during interview All interviews were transcribed and coded by the first author following a content analysis approach (16), meaning that codes were assigned inductively, as well as deductively, based on the process evaluation framework. After initial codes were assigned, categories Finally, the results of the needs assessment were linked to the health planning and quality of life assessment and planning program[16].

\section{Step 2: Matrix (identification of outcomes, performance objectives and change objectives)}

The next step in the process involved the detailed specification of outcomes for the intervention[17]. Following the specification of outcomes, performance objectives for each of the specified outcomes were defined. Performance objectives are a means of identifying the precise behaviours that must occur to achieve the specified outcomes. The final stage in this process required that the objectives of the intervention were stated in terms of the actual changes that need to occur in the theoretical determinants of behaviour. This is vital as it allows the intervention developer to identify the exact constructs that need to change to have an effect on the performance objective and the programme outcome as a whole. [18] his process resulted in a matrix specifying the performance objectives, the theoretical determinant of that behaviour and change objectives(17). 


\section{Stage 3: selecting methods and practical strategies}

In the third step, while the planning team predicted the ideas of the plan, the theoretical methods affecting the determinants of change were selected, and practical solutions were selected, and the evaluation program was designed to implement the predicted theoretical methods.

\section{Step 4: program production}

At this step of designing the intervention program, while holding a group meeting with the participants and considering their priorities and suggestions, the implementation, scope, and implementation sequence themes of the program were identified along with the constraints. For instance, if one part of the program had been planned for the school program during the school year, the resources needed by the principal and teacher along with the financial constraints of the program and the stages of program implementation were determined. The planning team then decided on the intervention methods to achieve the goals of change, and finally pre-tested the messages and other parts of the program before final production.

\section{Step 5: Program implementation}

At this step, the tasks of the individuals and what they must do so that the outcome is fully met and implemented acceptably were determined. Then similar to Step 2, matrix planning was defined to guide the intervention program. In this matrix, the operational goals and determinants were determined for adoption, implementation and maintenance of the program. For instance, determinants responded to the question why do decision makers decide to use the program and why those in charge try to make sure the program continues over time? The answers to these questions determine the adoption, implementation, and maintenance of the program.

\section{Stage 6: evaluation planning}

In the final step, the assessment program was defined to determine the effectiveness of the program, and the extent to which the performance goals and objectives were changed. Assessment questions were identified from the defined outcomes and objectives, and a criterion was identified [19].

The results of the first step, needs assessment: The results of a review of studies ( 15 related papers) showed that Students' information on how to use a backpack and related injuries was low. Moreover, the majority of teenage students does not have a proper definition of backpack and how to use it, how to use a backpack bag, A variety of backpack bags. In this study, mothers and school health educators were the most reliable channel of transmission of information.

\section{Results}

\section{Results of the first step}


Key findings emerged from the needs assessment:

The systematic review conducted as part of this programme of plan, the findings of the present review indicated two outcomes by considering the impact of the backpack on musculoskeletal injuries and pains among adolescents. The results of the review studies specified that there was a statistically significant positive relationship between the prevalence of musculoskeletal injuries and pain using a backpack among most of the male and female adolescents.

The first intervention mapping step of conducting a needs assessment helps to identify the health problem and its related behavioral and environmental determinants for the at-risk population the results were categorized into 3 outcomes:1- Increasing student information about backpacks and musculoskeletal injuries 2- Increasing student information about all kinds of backpacks 3-Proper use of backpacks. Also The literature suggests that there are a range of barriers. This mapping process revealed that the main barriers fell into the theoretical categories of knowledge, beliefs about capabilities (selfefficacy), environmental context and resources. Facilitators reversal of these barriers; for example, if a barrier was a lack of knowledge about healthy behavior about musculoskeletal health and how to use a school bag, a facilitator was improved knowledge of what healthy behavior about musculoskeletal health or how to use a school bag of course in simple language. However, other facilitators included the use of rewards, such as sticker charts for children.

\section{1- Increasing student information about backpacks}

The weight of backpack and musculoskeletal symptoms related to backpack carriage on student [19]. also back pain is a common affliction and a leading cause of disability in adults, but only recently has back pain been documented in teenage students [20]. ergonomics awareness and posture training is an important preventive approach to back pain, it is important for teenage students to learn about the structure of spine and back care [19]. One common suspect for back pain in children is the school backpack, which has also received a greater deal of attention in the past few years [21]. A study in Italy found that the average load of backpack was $22 \%$ of the student's weight and that $1 / 3$ of the student surveyed carried excess of $30 \%$ of their body weight at least one time per weak, their point prevalent for reporting back pain was nearly $16 \%$. With life time prevalence is estimated to be $48 \%$ [22].

\section{Increasing student information about All kinds of backpacks}

A backpack is a cloth sack put on somebody's back. It usually has two straps that go over the shoulders. People often use backpacks on camping trips, hikes, or any form of outdoor activity where people need to carry many things. Backpacks are also being used in the military by soldiers. It can be also used in school, or in this case, it also called a book bag or backpack [4].It is important to increase students' knowledge of the types of backpacks and standard backpacks while most students choose their backpack according to its appearance why so studies show that most bags and school backpacks are not standard [23]. 


\section{Proper use of backpacks}

When the backpack load is greater than the carrying capacity of the muscle teenage students, there is overhead, reflecting the spine, causing pain, structural changes or dysfunction [24] Special attention has been paid when the weight is more than $15 \%$ of their body mass. According to the Italian Backpack Study, in Italy students carry backpacks with $22 \%$ of their body weight, and $34.8 \%$ of them carry backpacks with weight corresponding to $30 \%$ of their body weight, at least once a week, exceeding even the proposed limits for adult also They found that when carrying backpack with a load of $15 \%$ of body weight major changes occurs in angles of the head, neck affect the posture [25].

\section{Results of the second step:}

The planning team drafted the performance goals based on theories of planned self-efficacy at the beginning of this phase according to the 3 individual outcomes of the program. Then, they got help from a three-person group including a health education specialist, an adolescent psychologist, and a health educator to evaluate the validity, and based on their views, the drafted performance goals were revised (Tables 1 and 2).

Table 1

Individual-level matrix the first behavioral consequence: Increasing teenage student's information about backpacks

\begin{tabular}{|c|c|c|c|}
\hline \multirow{2}{*}{$\begin{array}{l}\text { Performance } \\
\text { Objective (PO) }\end{array}$} & Determinant 1 & Determinant 2 & Determinant 3 \\
\hline & Awareness & Self-efficacy & Behavior barriers \\
\hline $\begin{array}{l}\text { Teenage students } \\
\text { know and express } \\
\text { tips about backpacks } \\
\text { and proper use }\end{array}$ & $\begin{array}{l}\text { Change objectives: } \\
\text { teenage students state the } \\
\text { weight of standard } \\
\text { backpack } \\
\text { Teenage students explain } \\
\text { musculoskeletal } \\
\text { symptoms related to } \\
\text { heavy backpack carriage }\end{array}$ & $\begin{array}{l}\text { Change objectives: } \\
\text { teenage students } \\
\text { regularly plan to use the } \\
\text { recommended about } \\
\text { proper use of backpack }\end{array}$ & $\begin{array}{l}\text { Change } \\
\text { objectives: } \\
\text { teenage } \\
\text { students' express } \\
\text { barriers to proper } \\
\text { use of backpack }\end{array}$ \\
\hline
\end{tabular}


Table 2

Interpersonal level matrix Behavioral outcome: Positive family support

\begin{tabular}{|c|c|c|c|}
\hline \multirow{2}{*}{$\begin{array}{l}\text { Performance } \\
\text { Objective } \\
\text { (PO) }\end{array}$} & Determinant 1 & Determinant 2 & Determinant 3 \\
\hline & Awareness & Self-efficacy & Behavior barriers \\
\hline \multirow{3}{*}{$\begin{array}{l}\text { Proper use } \\
\text { of } \\
\text { backpacks }\end{array}$} & Change objectives: & Change objectives: & Change objectives: \\
\hline & $\begin{array}{l}\text { Teenage students show } \\
\text { proper use of } \\
\text { backpacks }\end{array}$ & $\begin{array}{l}\text { Teenage students are sure } \\
\text { can use their backpacks } \\
\text { properly }\end{array}$ & $\begin{array}{l}\text { Teenage students name } \\
\text { barriers use backpacks } \\
\text { properly }\end{array}$ \\
\hline & $\begin{array}{l}\text { Teenage students } \\
\text { express proper use of } \\
\text { backpacks }\end{array}$ & & \\
\hline
\end{tabular}

\section{Performance Objectives:}

In order to specifically target the behavioral change among teenage students, the research team next identified performance objectives that would clarify the exact behavior performance expected of an individual affected by the intervention. In this case, they asked themselves what the target population exposed to the intervention must do in order to engage.

\section{Determinants of musculoskeletal health:}

Once the target behavior and performance objectives had been specified, the next step was to identify determinants, that is, the factors found to be associated with the performance of the behavior. The research team undertook a review of available evidence about determinants contributing to musculoskeletal health. knowledge, beliefs about capabilities (self-efficacy), environmental context and resources. was the most important determinants tables 1 and 2 provides an example of the matrices of the performance objectives, which is to plan musculoskeletal health.

\section{Results of step three:}

In this step, the theoretical methods and practical applications for each determinant were defined with the participation of the planning team (Table 3). When examining various behavioral theories that addressed behavior barriers $[44,45]$. The third step in intervention mapping consists of determining which theories and theoretically based methods would be most effective in achieving the intervention's performance objectives and then deciding which practical strategies would best operationalize those theoretical methods. Considering these theoretical determinants, it was decided that practical strategies, such as using workbook activities, work/note books to allow mothers or teenagers to specify a series of implementation how healthy behaviors about and encouraging the use of reminders and environmental cues to prompt healthy behaviors may be useful. Furthermore, the use of leaflets can be used to convey the costs and benefits of engaging in healthy behaviors. not engaging . 
Table 3

Theoretical methods, practical applications, communication tools channels

\begin{tabular}{|lll|}
\hline $\begin{array}{l}\text { Performance Objective } \\
\text { (P0) }\end{array}$ & Determinant 1 & Determinant 2 \\
\cline { 2 - 3 } & Awareness & Self-efficacy \\
\hline $\begin{array}{l}\text { Family members talk to } \\
\text { teenage students about } \\
\text { their safe backpack and } \\
\text { all kinds of it }\end{array}$ & $\begin{array}{l}\text { Change objectives: } \\
\text { Mothers are confident in their } \\
\begin{array}{l}\text { Mothers support teenage } \\
\text { students in maintaining communicate with } \\
\text { a healthy diet }\end{array}\end{array}$ & $\begin{array}{l}\text { Change objectives: } \\
\text { Teenage students } \\
\text { have a positive relationship with their } \\
\text { teenage students, they prefer non- } \\
\text { standard bags }\end{array}$ \\
\hline $\begin{array}{l}\text { Change objectives: } \\
\text { ability to support their teenage } \\
\text { students to buy a beautiful } \\
\text { ergonomic backpack }\end{array}$ & $\begin{array}{l}\text { Change objectives: } \\
\text { to support their Teenage students to } \\
\text { buy a beautiful ergonomic backpack }\end{array}$ \\
\hline
\end{tabular}

\section{Results of step four:}

Step 4 of intervention mapping entails determining the scope and sequence of the intervention's components and producing the materials for Intervention (27-28).

The programme development involved two groups of people including programme developers, health workers. The programme developers were recruited from the University of Medical Sciences on the basis of their expertise in curriculum development and experience in developing teenagers and Musculoskeletal health related programmes.

Health workers came from University of Medical Sciences and And the Department of Education or the school representative. These parties formed a programme development team that met on a regular basis to review progress on the programme development process until the programme was produced.

The programme comprised five lessons delivered in 5 sessions over 7 hours. The lessons were delivered in two modes. First, there were classroom sessions involving teacher and mothers group discussions, storytelling, role-plays, motion graphic and hand book.

Secondly, teenagers were given homework book (These books were prepared by experienced people) assignments to be accomplished at home with the help of mothers. Mothers were informed of the homework book assignments by letters that were sent through their children. The aim of homework book assignments was to foster The plan involved implementation objectives, methods and strategies.

The planning team involved researchers, teachers, students, and government officials from health and health workers. Prior to programme implementation, mothers and teachers were trained on the content and facilitation skills. Training activities included administration of pre-test and post-test assignments. These were aimed at measuring teachers' knowledge about teenagers and Musculoskeletal health. The training programme was also used to pre-test the programme materials as well as teaching methods and 
strategies among mothers and teachers. Teachers were asked to comment on the attractiveness, completeness, suitability and relevance of the programme materials and methods to teenagers. A professional graphic designer was employed to draw illustrations to enhance the attractiveness and easy understanding of the teenagers. The students, for example, advised on the suitability of the learning materials, while teachers advised on the appropriate time and mode of programme implementation. The health workers played a key role. that they were relevant to social-cultural context of the implementation setting.

\section{Results of Step Five:}

it has been recommended that health promotion interventions should to provide a community-based intervention with regard to the universal intervention, it was decided to deliver the intervention through officials and health school health workers that already have regular contact with mothers and teenagers. In respect to the targeted programme delivered through parenting programmes, it was decided that the parenting programme facilitators would be best placed to deliver the intervention[26].

\section{Results of the sixth stage:}

Since one of the significant goals of evaluation is using evaluation results [27], at this stage, the planning team identified the evaluation stakeholders - such as planners, study participants, program managers and executives - to evaluate the effect of the program, designed questions based on outcomes, performance goals, and individual and environmental determinants (Table 4). In this study, 30 students were selected to participate in the study performance. Those included attended training sessions for 4 weeks once a week [27] (not more than 5\% of participants should have been absent in each training session).

Table 4 Evaluation of outcome, effect, and program process (sample questions) 
Evaluating program outcomes

Life quality How much has the adherence to teenage student's health behavior changed? (use proper backpack)

Personal level

Do the teenage students do more healthy behaviors (use proper backpack) after program implementation compared to before program implementation?

Interpersonal level

Do mothers have more verbal and nonverbal communication with their teenage students (about use proper backpack) after program implementation?

Assessment of the effect of program based on functional goals

Personal level

Do the teenage students adhere to health behaviors (use proper backpack) more after program implementation compared to before?

Interpersonal level

Do mothers support teenage students about ergonomic backpack training and shopping after implementing health behaviors more compared to before the implementation?

Assessment of the effect of change-based programs

Personal level

Do the teenage students state the significance of observing health behaviors (use proper backpack) after the program is implemented?

Interpersonal level

Do the mothers consider it important to have effective conversations after the implementation? (use proper backpack)

Determinant-based program effect assessment

$\begin{aligned} & \text { Personal Awareness } \\ & \text { level }\end{aligned} \quad \begin{aligned} & \text { Do teenage students report the disadvantages Non-ergonomic } \\ & \text { backpack after the program is implemented? }\end{aligned}$

Self- $\quad$ Do the teenage students feel more confident about adhering to

efficacy healthier behaviors (use proper backpack) after the program compared to before?

Behavioral Do the teenage students develop an appropriate program to reduce the barriers barriers to adhering to healthier behaviors (use proper backpack) than before after implementing the program?

Interpersonal Self- Do the mothers express greater confidence in supporting their teenage level efficacy students after the program has been implemented compared to before? (use proper backpack)

Assessment of program development process

Attainment

What proportion of the teenage student's community participated in the program?

Accuracy Is the educational curriculum done according to the protocol?

Organizing the program Has the executive schedule been developed for the musculoskeletal health program

Program Index 
Improving mothers' behavior by $30 \%$ over one period of program implementation

Improving the behavior of teenage students by $30 \%$ over one period of program implementation

Curriculum index: Individual and interpersonal performance change was determined. According to the studies conducted, the mothers and teenage student's behavior improvement index was considered to be $30 \%$ over one period of program implementation [28]. Then, a measurement tool was designed to evaluate the outcomes, behaviors, and determinants of personal and interpersonal levels. The evaluation program was implemented three months later, and to examine the made changes, the experimental study design with randomly dividing the participants into intervention and control groups was used [27].

\section{Discussion}

This program was done to design and develop How to use a backpack and reduce teenager musculoskeletal damage training program using IMA. The results indicated that IMA is a good step-bystep framework for developing a systematic and community-based program in teenage students. Moreover, IMA provides a practical and usable guide to adapt and promote health promotion programs for other planners to be used elsewhere [29]. It has to be noted that IMA is highly practical and user friendly [16]. Our results indicated that IMA can help develop a theory-based and evidence-based problemsolving approach [30], produce outcomes, performance goals, change objectives, determinants, theoretical change methods, and practical applications and evaluation.

\section{Conclusion}

Intervention Mapping has been successfully used to plan, implement and evaluate educational interventions. This study has provided a good understanding of the role of intervention mapping in designing educational interventions for teenage student, and a good foundation upon which subsequent reviews can be guided.

\section{Abbreviations}

TSMH: teenage students' musculoskeletal health;

TSTP: teenage students training program;

AIMA: application of intervention mapping approach;

\section{Declarations}

\section{Acknowledgments}

The authors of this study are thankful to all participants in the present study. 


\section{Authors' Contributions}

NN, AZ and SST conceived and designed the study and finalized the methodology and tools used. NN and AZ collected the data and analyzed and drafted the manuscript. SST and JA helped with critical comments and drafting the final version of the manuscript. All the authors made significant contributions in the manuscript writing and finalizing of the manuscript. The final manuscript has been read and approved by all the authors.

\section{Funding}

This study did not receive any grant from funding agencies.

\section{Availability of data and materials}

The datasets using in the study are available from the corresponding author on reasonable request.

\section{Ethics approval and consent to participate}

Ethics approval project approved the under the Code of (IR.AUMS.REC. 1399.064) in Ardabil University of Medical Sciences.

\section{Consent to publish}

All participants consented verbally to the publication of the interview data.

\section{Competing interests}

The authors declare that they have no competing interests.

\section{References}

1. Sistani N, Khoi M, Taghdisi M. Promoting knowledge, attitude and practices (KAP) of the mothers in their Girls' pubertal health based on peer education approach. J Babol Univ Med Sci. 2010;11(6):339.

2. Mansoorian M, GhasemiMS, Forough B, Dehghan N. Evaluating the impact of a new ergonomic backpack designed on foot plantar pressure and perceived comfort by its users. Iran Occup Health. 2018;15(5):59-68.

3. Fernandez ME, Ten Hoor GA, van Lieshout S, Rodriguez SA, Beidas RS, Parcel G, Ruiter RA, Markham $\mathrm{CM}$, Kok G. Implementation mapping: using intervention mapping to develop implementation strategies. Front Public Health. 2019;7:158.

4. Kistner F, Fiebert I, Roach K, Moore J. Postural compensations and subjective complaints due to backpack loads and wear time in schoolchildren. Pediatr Physical Therapy. 2013;25(1):15-24.

5. Grarmaroudi GR, Makarem J, Alavi SS, Abbasi Z. Health related risk behaviors among high school students in Tehran, Iran. Payesh (Health Monitor). 2010;9(1):13-9. 
6. Peters G-J. A practical guide to effective behavior change: how to identify what to change in the first place. European Health Psychologist. 2018;16(4):142-55.

7. Farahani FKA, Cleland J, Mehryar AH. Associations between family factors and premarital heterosexual relationships among female college students in Tehran. Int Perspect Sexual Reproduct Health. 2011;37(1):30-9.

8. Schuiling. Women's Gynecologic Health. Jones \& Bartlett Learning. p. 22. ISBN 978-1-284-12501-6. The changes that occur during puberty usually happen in an ordered sequence, beginning with thelarche (breast development) at around age 10 or 11, followed by adrenarche (growth of pubic hair due to androgen stimulation), peak height velocity, and finally menarche (the onset of menses), which usually occurs around age 12 or 13. 2016.

9. Shamsoddini A, Hollisaz M, Hafezi R. Backpack weight and musculoskeletal symptoms in secondary school students, Tehran, Iran. Iran J Public Health. 2010;39(4):120-8.

10. Lloyd-Smith W. Evidence-based practice and occupational therapy. British J Occupat Therapy. 1997;60(11):474-8.

11. Crombie IK, Harvey BJ. The pocket guide to critical appraisal: a handbook for health care professionals. Canadian Med Associat J. 1997;157(4):448-506.

12. Navuluri N, Navuluri RB. Study on the relationship between backpack use and back and neck pain among adolescents. Nurs Health Sci. 2006;8(4):208-15.

13. Haselgrove C, Straker L, SmithA, O'Sullivan P, Perry M, Sloan N. Perceived school bag load, duration of carriage, and method of transport to school are associated with spinal pain in adolescents: an observational study. Australian J Physiotherapy. 2008;54(3):193-200.

14. ChowD, Ou Z, Wang X, Lai A. Short-term effects of backpack load placement on spine deformation and repositioning error in schoolchildren. Ergonomics. 2010;53(1):56-64.

15. Standards JCoNHE. National health education standards: Achieving excellence: AmericanCancer Society; 2007. Retrieved May 1, 2009, from https://www.cdc.gov/HealthyYouth/SHER/standards/index.htm p.

16. Foxcroft DR, Ireland D, Lister-Sharp DJ, Lowe G, Breen R. Longer-term primary prevention for alcohol misuse in young people: a systematic review. Addiction. 2003;98(4):397-411.

17. Kiyalashki A. Postmenopausal menstrual disorders among female students of Babol high schools in year 2000. Master thesis of Midwifery. Iran Univ Med Sci, Tehran, Iran. 2000.

18. Kok G, Lo SH, Peters G-JY, Ruiter RA. Changing energy-related behavior: An Intervention Mapping approach. Energy Policy. 2011;39(9):5280-6.

19. Bartholomew LK, Parcel GS, Kok G. Intervention mapping: a process for developing theory and evidence-based health education programs. Health Educ Behav. 1998;25(5):545-63.

20. Frumkin H, Geller RJ, Rubin IL, Nodvin J. Safe and healthy school environments: Oxford University Press; 2006. 
21. Murphy S, Buckle P, Stubbs D. Classroom posture and self-reported back and neck pain in schoolchildren. Applied Ergonom. 2004;35(2):113-20.

22. Wyatt LH. Handbook of clinical chiropractic care. Jones \& Bartlett Learning; 2005.

23. Negrini S, Carabalona R. Backpacks on! Schoolchildren's perceptions of load, associations with back painand factors determining the load. Spine. 2002;27(2):187-95.

24. Peters G-JY, De Bruin M, Crutzen R. Everything should be as simple as possible, but no simpler: towards a protocol for accumulating evidence regarding the active content of health behaviourchange interventions. Health Psychology Rev. 2015;9(1):1-14.

25. Ramprasad M, Alias J, Raghuveer A. Effect of backpack weight on postural angles in preadolescent children. Indian Pediatr. 2010;47(7):575-80.

26. Precenzano F, Ruberto M, Parisi L, Salerno M, Maltese A, D'alessandro I, et al. ADHD-like symptoms in children affected by obstructive sleep apnea syndrome: a case-control study. Acta Med Mediterranea. 2016;32:1755-9.

27. Grunbaum JA, Kann L, Kinchen SA, Williams B, Ross JG, Lowry R, et al. Youth risk behavior surveillance-United States, 2001. J School Health. 2002;72(8):313-28.

28. Herbold NH, Frates SE. Update of nutrition guidelines for the teen: trends and concerns. Current Opinion Pediatr. 2000;12(4):303-9.

29. NicklasTA, Bao W, Webber LS, Berenson GS. Breakfast consumption affects adequacy of total daily intake in children. J Am Dietetic Associat. 1993;93(8):886-91.

30. Azmoude E, Jafarnejade F, Mazlom SR. The predictors for maternal self-efficacy in early parenthood. J Mid Reproduct Health. 2015;3(2):368-76.

31. Ali TS, Rizvi SN. Menstrual knowledge and practices of female adolescents in urban Karachi, Pakistan. J Adol. 2010;33(4):531-41.

32. Sedghi Sabet M, Hasavari F, Saied Fazel Poor F. A Survey Of Knowledge, Attitude, And Health Behaviour Of Girl Studeuts About Puberty. J Guilan Univ Med Sci. 2003;12(47):31-8.

33. Peters G-J. A practical guide to effective behavior change: howto identify what to change in the first place. European Health Psychologist. 2018;16(4):142-55. 